\title{
2085 Strain encoded magnetic resonance imaging (SENC) assessment of regional ventricular function in pulmonary arterial hypertension - initial results
}

\author{
Monda L Shehata*, Lynette Brown, Jens Vogel-Claussen, Joao AC Lima, \\ Reda E Girgis, Paul M Hassoun, David A Bluemke and Nael F Osman
}

Address: Johns Hopkins University, Baltimore, MD, USA

* Corresponding author

from I th Annual SCMR Scientific Sessions

Los Angeles, CA, USA. I-3 February 2008

Published: 22 October 2008

Journal of Cardiovascular Magnetic Resonance 2008, IO(Suppl I):A354 doi:I0.I I86/I532-429X-I0-SI-A354

This abstract is available from: http://jcmr-online.com/content/I0/SI/A354

(c) 2008 Shehata et al; licensee BioMed Central Ltd.

\section{Introduction}

Evaluation of right ventricular (RV) function is an important prognostic factor in many cardiac and/or pulmonary conditions. Pulmonary arterial hypertension (PAH) is a major cause of RV dysfunction and failure, which in turn affects left ventricular performance due to ventricular interdependence. Cardiac MRI is a reproducible three dimensional tomographic tool providing accurate measurements of global right ventricular function. For the RV, measuring regional strain using MRI (e.g., using tagging) is limited by thin wall. Strain encoded MRI (SENC), however, enables the quantification of RV strain (1) in the longitudinal direction (Ell), which is the main contributor to $\mathrm{RV}$ contractile function. On the other hand, fast strain encoded MRI (fSENC) allows for single heartbeat, non breath hold, acquisitions; thus providing an alternative to patients experiencing difficulty in breath holding (2).

\section{Purpose}

To analyze the effect of pulmonary arterial hypertension on myocardial strain using strain encoded MRI.

\section{Methods}

Healthy volunteers were imaged using $13 \mathrm{sec}$ breath hold SENC acquisition (TR $=22 \mathrm{msec}, \mathrm{TE}=0.8 \mathrm{msec}$, flip angle $=40^{\circ}, \mathrm{FOV}=350 \times 350 \mathrm{~mm}$ at a spatial resolution of $3 \times$ $3 \mathrm{~mm}$ ). Fast SENC (fSENC) acquisition (TR $=32 \mathrm{msec}$, TE $=0.8 \mathrm{msec}$, flip angle $=40^{\circ}, \mathrm{FOV}=150 \times 150 \mathrm{~mm}$ and spatial resolution of $4 \times 4 \mathrm{~mm}$ ) was used to scan patients with catheterization established diagnosis of PAH (mean \pm SD pulmonary artery pressure $[\mathrm{PAP}]=34.25 \pm 10.6 \mathrm{~mm}$ $\mathrm{Hg})$. Both groups were scanned at $3 \mathrm{~T}$ MRI. Three shortaxis slices at the base, mid and apical regions were acquired for each subject. Image analysis was performed using custom software. Left ventricular Ell was quantified from six basal, six mid and four apical regions respectively. Ell in the RV free wall was measured at 5 equidistant segments starting from the anterior septal insertion and ending at the posterior septal insertion. At each segment, two measurements of Ell were averaged to calculate peak systolic Ell, defined from cine SENC and fSENC images as strain values at peak contraction. In our analysis, we excluded two suboptimal apical slices from volunteer group as well as two anterior right ventricular segments from patient group passing through RV out flow tract plane. Peak systolic Ell values of the LV and RV regions in patients were compared to corresponding regions in control group using unpaired Student-t test.

\section{Results}

In four PAH patients with catheter proven disease, significantly low RV strain values were noted at the basal anterior septal insertion, basal anterior wall, mid anterior septal insertion and mid anterior free wall compared to control groups $(\mathrm{n}=6$, mean $\pm \mathrm{SD}=-13.4 \pm 2.4$ compared to $-20.1 \pm 2.2, \mathrm{p}=0.04,-16.8 \pm 4.01$ compared to $-22.3 \pm$ $0.98, \mathrm{p}=0.012,-14.4 \pm 2.25$ compared to $-18.9 \pm 3.01, \mathrm{p}$ $=0.03$; and $-13.3 \pm 3.7$ compared to $-20.67 \pm 2.02, \mathrm{p}=$ 
0.02; respectively) (Figure 1). Also, antero-septal and infero-septal regions at basal ventricle showed less Ell strain values in patients compared to controls (mean \pm SD $=-12.6 \pm 4.2$ compared to $-18.9 \pm 2.7 \mathrm{p}=0.049$ and -15.1 \pm 5.7 compared to $-20.9 \pm 1.9, \mathrm{p}=0.046$, respectively) (Figure 2). Areas of reduced strain were in a similar distribution to myocardial scar at the RV insertion points.

\section{Conclusion}

Right and left ventricular longitudinal strain measured by SENC MRI shows significant regional function discrepancy in PAH patients compared to controls. Decreased strain was noted at the RV basal and mid anterior septal insertion points, as well as the adjacent anterior region. In LV, decreased Ell was notable at basal interventricular septum, and correlated in extent with areas of myocardial scar (Figure 3).

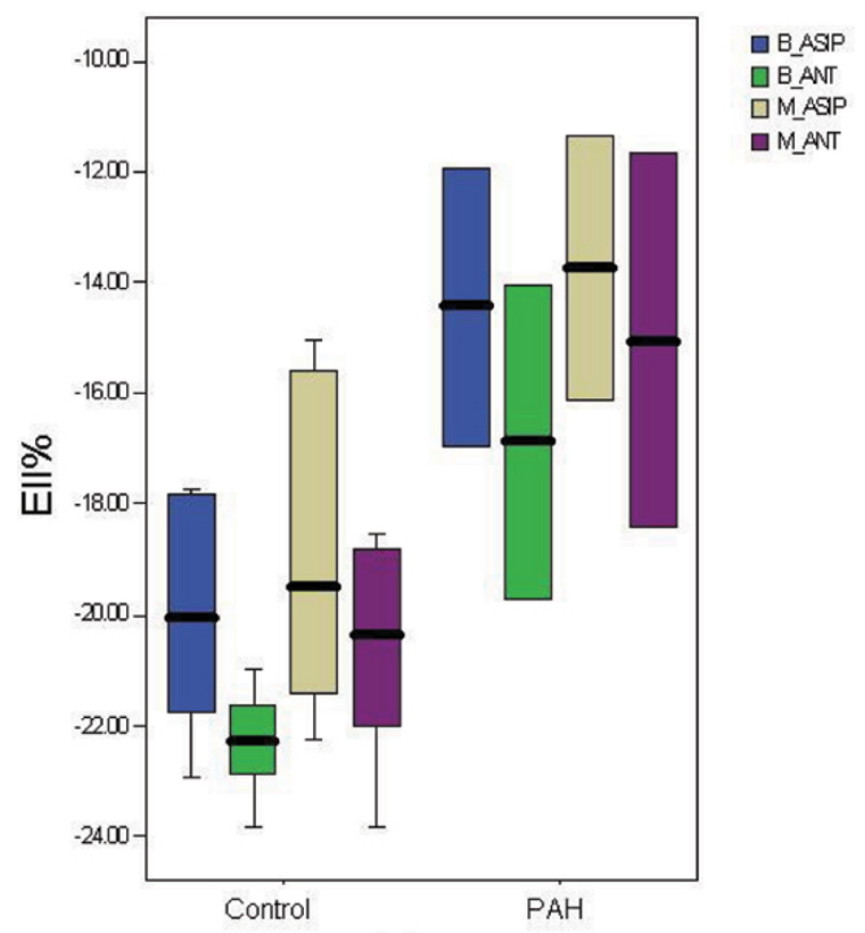

Figure I

Comparison of EII at basal and mid RV anterior septal insertion (ASIP), and anterior regions (ANT).

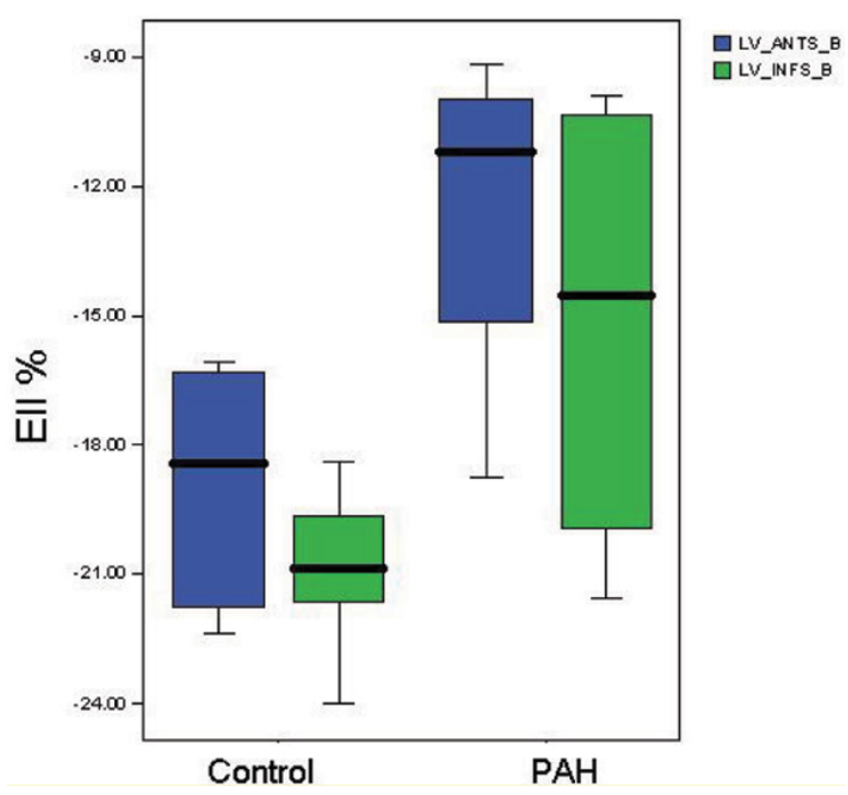

Figure 2

Comparison of Ell at LV basal antero-septal (ANTS) and infero-septal (INFS) regions. 


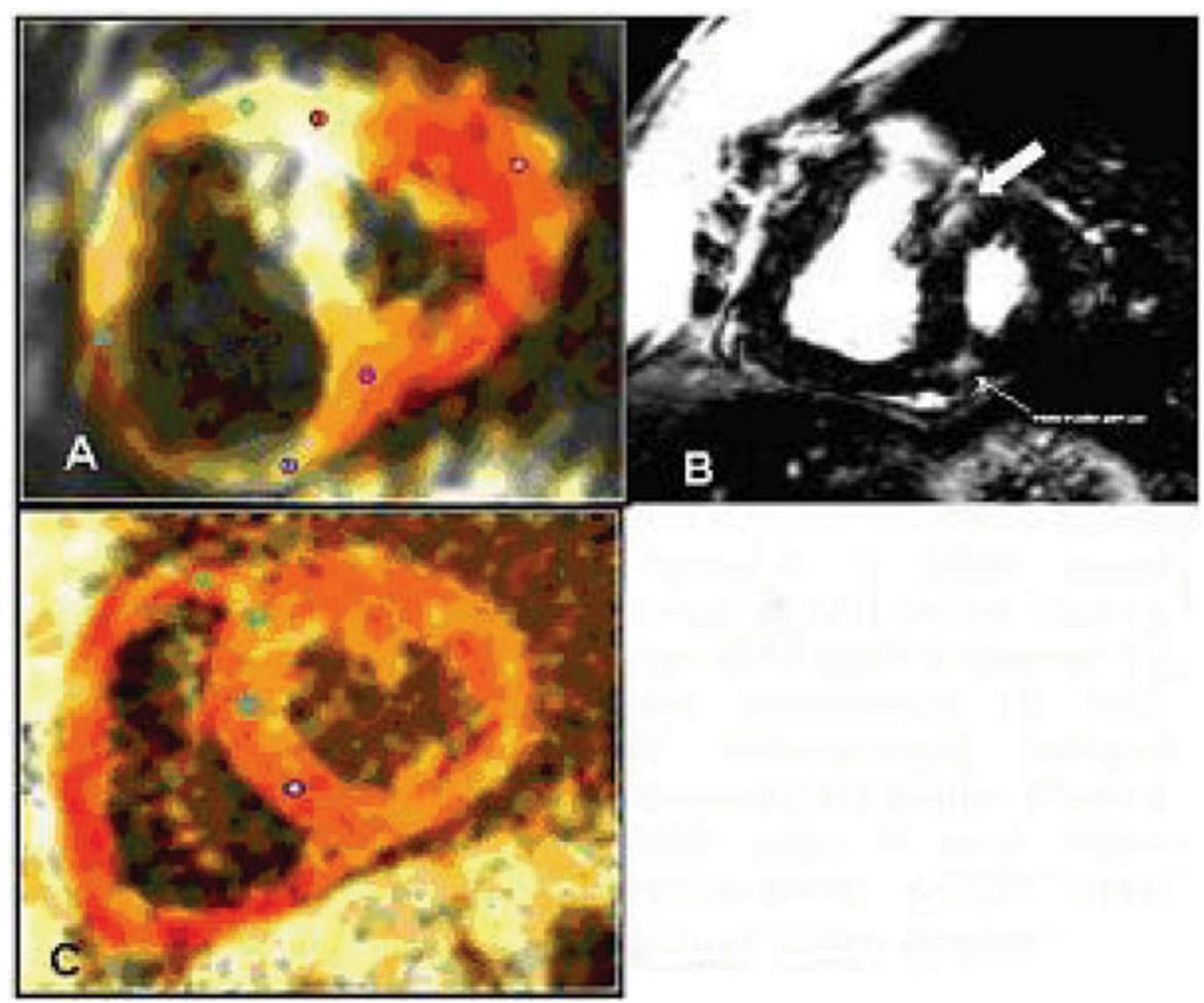

Figure 3

(A) $f$ SENC basal image of PAH patient showing decreased strain at anterior RV and antero-septal LV walls. (B) Corresponding delayed enhancement image showing high signal at same region (block arrow). (C) SENC basal slice of normal volunteer.

Publish with Biomed Central and every scientist can read your work free of charge

"BioMed Central will be the most significant development for disseminating the results of biomedical research in our lifetime. " Sir Paul Nurse, Cancer Research UK

Your research papers will be:

- available free of charge to the entire biomedical community

- peer reviewed and published immediately upon acceptance

- cited in PubMed and archived on PubMed Central

- yours - you keep the copyright
BioMedcentral 